\title{
SUPPLY CHAINS IN NETWORK ECONOMY
}

A supply chain can be shown as a set of units interconnected by material, financial, information and decision flows from initial suppliers to ultimate customers. Supply chain management is more and more affected by network business environment and by information and communication technologies. The paper analyzes a combination of non-cooperative and cooperative decision making of supply chains in network economy.

Keywords: Supply chain, network economy, e-commerce, non-cooperative and cooperative decision-making

\section{Supply chain management}

Supply chain management is now seen as a governing element in strategy and as an effective way of creating value for customers. Supply chain management benefits from a variety of concepts that were developed in several different disciplines as marketing, information systems, economics, system dynamics, logistics, operations management, and operations research. There are many concepts and strategies applied in designing and managing supply chains (see [13]). The expanding importance of supply chain integration presents a challenge to research to focus more attention on supply chain modeling (see [14], [17]).

A structure of supply chains is composed of potential suppliers, producers, distributors, retailers and customers etc. The units are interconnected by material, financial, information and decisional flows (see Fig.1).

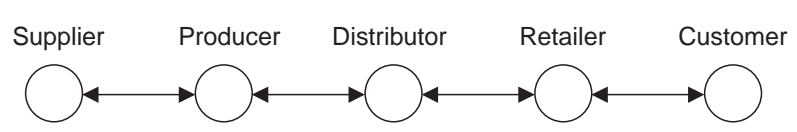

Fig.1. Structure of a supply chain

Most supply chains are composed of independent units with individual preferences. Each unit will attempt to optimize its own preference. Behavior that is locally efficient can be inefficient from a global point of view. In supply chain behavior are many inefficiencies. An increasing number of companies in the world subscribe to the idea that developing long-term coordination and cooperation can significantly improve the efficiency of supply chains and provide a way to ensure competitive advantage.

Double marginalization is a well-known cause of supply chain inefficiency (see [14]). Double marginalization problem occurs whenever the supply chain's profits are divided among two or more firms and at least one of the firms influences demand. Each firm only considers its own profit margin and does not consider the supply chain's margin.
We consider a supply chain with a producer and a retailer that sells a product. The producer produces each unit for a cost $\mathrm{c}$ and sells each unit to the retailer for a wholesale price $p^{(1)}$. The retailer chooses an order quantity $x$ and sells $x$ units at price $p^{(2)}(x)$, assuming that $p^{(2)}(x)$ is decreasing, concave and twice differentiable function.

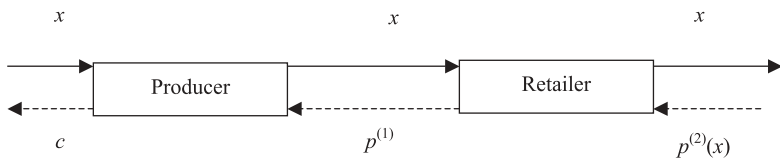

Fig. 2. Double marginalization problem

A centralized solution assumes a single agent has complete information and controls the entire supply chain (this is referred as the first-best solution) to maximize supply chain profit

$$
z(x)=x\left(p^{(2)}(x)-c\right) .
$$

The centralized solution of the problem is denoted $x^{0}$.

A decentralized solution assumes the firms have incomplete information and make choices with the objective of maximizing their own profits. The retailer's profit and the producer's profit are

$$
z_{r}(x)=x\left(p^{(2)}(x)-p^{(1)}\right), \quad z_{p}(x)=x\left(p^{(1)}-c\right)
$$

The decentralized solution of the problem is denoted $x^{*}$.

If the centralized and decentralized solutions differ, we investigate how to modify the firm's payoffs so that a new decentralized solution corresponds to the centralized solution. It can be shown that the retailer orders less than the supply chain optimal quantity $\left(x^{0}>x^{*}\right)$ whenever the producer earns a positive profit and it holds

$$
z\left(x^{0}\right)>z_{r}\left(x^{*}\right)+z_{p}\left(x^{*}\right)
$$

\footnotetext{
* Petr Fiala

Department of Econometrics, Faculty of Informatics and Statistics, University of Economics, W. Churchill Sq. 4, 13067 Prague 3 E-mail: pfiala@vse.cz
} 
Marginal cost pricing $\left(p^{(1)}=c\right)$ is one solution to double marginalization problem, but the producer earns a zero profit. A better solution is a profit sharing contract, where the producer earns $v z(x)$ and the retailer earns $(1-v) z(x)$, for $0 \leq v \leq 1$. The wholesale price $p^{(1)}$ is now irrelevant to each firm's profit and the supply chain earns the optimal profit.

In today's global world there are many shifts. Supply chain management is more and more affected by network business environment and by information and communication technologies (see [13]). The global production systems move from rigid supply chain structures into globally distributed dynamic networks of agile business units. The shift in power from the supplier to the customer should lead to analyzing supply chains from a demand perspective. The paper analyzes a combination of non-cooperative and cooperative decision-making of supply chains in network economy.

\section{Network economy environment}

The network economy (see [6], [9] [11], [12]) is a term for today's global relationship among economic subjects characterized by massive connectivity. The central act of the new era is to connect everything to everything in deep web networks at many levels of mutually interdependent relations, where resources and activities are shared, markets are enlarged and costs of risk are reduced. Network industries play a crucial role in modern life. Today network systems provide the infrastructure and foundation for the functioning of societies and economies. They come in many forms and include physical networks such as: transportation and logistical networks, communication networks, energy networks, as well as more abstract networks comprising: economic and financial networks, environmental networks, social, and knowledge networks. The decisions made by the users of the networks, in turn, affect not only the users themselves but others, as well, in terms of profits and costs, timeliness of deliveries, the quality of the environment, etc. The behavior of the users of the networks themselves may be non-cooperative. One of the principal facets of the network economy is the interaction among the networks themselves. The unifying concept of global networks with associated methodologies (see [10]) allows exploring the interactions among such networks as transportation networks, telecommunication networks, as well as financial networks.

Network economy drives and is driven by dramatic acceleration in technological innovation, in information and communication technologies especially. New technologies provide a permanent feedback that enables activity modifications and quick responses and therefore fundamentally change business models. Business process modeling is the using of models and methods for understanding and change of the processes in relation to information systems of firms. The relation between business models and information systems becomes more and more tighter. E-business (see [16]) can enhance supply chain management decision making by making it possible to collect real time information and access and analyze the data in order to facilitate cooperation between trading partners in a supply chain. Using technology to connect ever more closely with network users creates "connectivity paradox" in which new realms of opportunity coexist with new forms of risk.

To achieve joint optimization of key supply chain decisions, it is preferable that there be a free flow of all relevant information across the entire network. Modeling of supply chains in network economy includes coordination of flows in different network structures and combination of non-cooperative and cooperative decisions. The presented model considers three-layer network structures of producers, retailers and customers. An overview of material, financial an informational flows is schematically shown in Fig. 3.

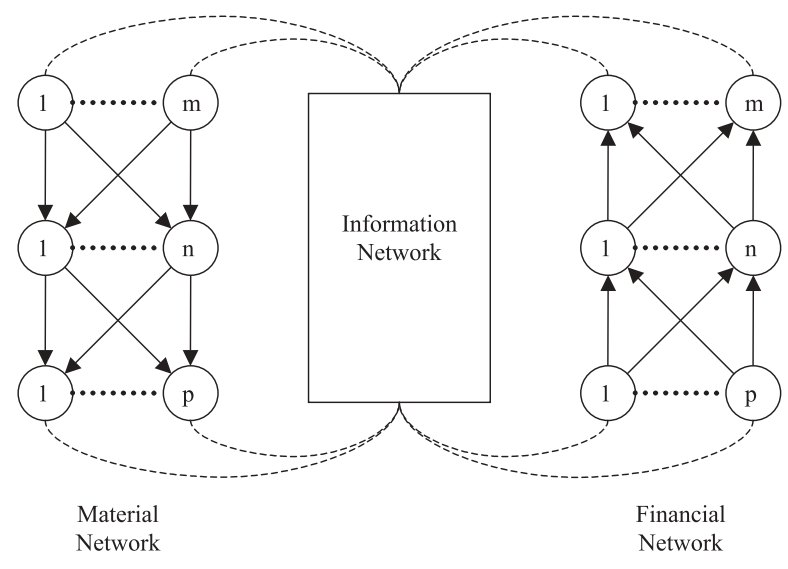

Fig.3. Material, financial an information flows in network environment

\section{Modeling of supply chain networks with e-commerce}

In the model we consider a three-layer network consists of $m$ producers $(i=1,2, \ldots, m)$, n retailers $(j=1,2, \ldots, n)$ and $p$ types of consumers (markets) $(k=1,2, \ldots, p)$. Producers sell the homogenous product to retailers by material and/or electronic channels. Producers can sell the product also directly to consumers by electronic channels. Retailers sell the product to consumers by material and/or electronic channels. Consumers can purchase the product in three ways, electronically from producers and/or retailers and by material channels from retailers. E-commerce is associated with the ability of business to perform transactions automatically. Electronic links between producers and retailers represent the business-to-business (B2B) component and electronic links between retailers and consumers represent the business-to-consumer (B2C) component of e-commerce.

Figure 3 depicts the three-layer network of interconnected producers, retailers and consumers. Continues lines represent material links and dash lines represent electronic links.

We define some notation:

$x_{i j}^{(1)}=$ a quantity of product shipment from producer $i$ to retailer $j$ by material links,

$y_{i j}^{(1)}=$ a quantity of product shipment from producer $i$ to retailer $j$ by electronic links, 


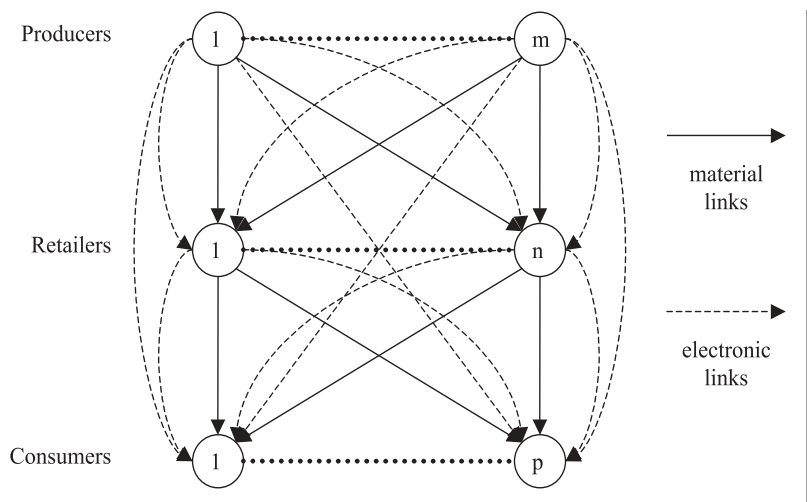

Fig. 4. Supply chain network with e-commerce

$x_{j k}^{(2)}=$ a quantity of product shipment from retailer $j$ to consumer $k$ by material links,

$y_{j k}^{(2)}=$ a quantity of product shipment from retailer $j$ to consumer $k$ by electronic links,

$y_{i k}^{(3)}=$ a quantity of product shipment from producer $i$ to consumer $k$ by electronic links,

$x^{(1)}=\sum_{i=1}^{m} \sum_{j=1}^{n} x_{i j}^{(1)}=$ a quantity of product shipment from all producers to all retailers by material links,

$y^{(1)}=\sum_{i=1}^{m} \sum_{j=1}^{n} y_{i j}^{(1)}=$ a quantity of product shipment from all producers to all retailers by electronic links,

$x^{(2)}=\sum_{j=1}^{n} \sum_{k=1}^{p} x_{j k}^{(2)}=$ a quantity of product shipment from all retailers to all consumers by material links,

$y^{(2)}=\sum_{j=1}^{n} \sum_{k=1}^{p} y_{j k}^{(2)}=$ a quantity of product shipment from all retailers to all consumers by electronic links,

$y^{(3)}=\sum_{i=1}^{m} \sum_{k=1}^{p} y_{i k}^{(3)}=$ a quantity of product shipment from all producers to all consumers by electronic links,

$p^{(1)}=p^{(1)}\left(x^{(1)}\right)=$ a price charged for the product transacted by material links by producers to retailers as a function of the total quantity $x^{(1)}$

$p^{(2)}=p^{(2)}\left(x^{(2)}\right)=$ a price charged for the product transacted by material links by retailers to customers as a function of the total quantity $x^{(2)}$

$q^{(1)}=q^{(1)}\left(y^{(1)}\right)=$ a price charged for the product transacted by electronic links by producers to retailers as a function of the total quantity $y^{(1)}$,

$q^{(2)}=q^{(2)}\left(y^{(2)}\right)=$ a price charged for the product transacted by electronic links by retailers to customers as a function of the total quantity $y^{(2)}$,

$q^{(3)}=q^{(3)}\left(y^{(3)}\right)=$ a price charged for the product transacted by electronic links by producers to customers as a function of the total quantity $y^{(3)}$, $c_{i}^{(1)}=$ production unit cost for producer $i$

$c_{j}^{(2)}=$ handling unit cost for retailer $j$,

$c_{i j}^{(1)}=$ transaction cost for production unit from producer $i$ to retailer $j$ by material links,

$d_{i j}^{(1)}=$ transaction cost for production unit from producer $i$ to retailer $j$ by electronic links,

$c_{j k}^{(2)}=$ transaction cost for production unit from retailer $j$ to consumer $k$ by material links,

$d_{j k}^{(2)}=$ transaction cost for production unit from retailer $j$ to consumer $k$ by electronic links,

$d_{i k}^{(3)}=$ transaction cost for production unit from producer $i$ to consumer $k$ by electronic links,

The model is a generalized oligopoly game (see [7]). The producers and retailers compete in a non-cooperative way. Nash equilibrium concept is used that each maximizes his profit given the actions of the others.

Quantities of production shipment are nonnegative variables and satisfy the obvious constraints

$$
\begin{aligned}
& \sum_{i=1}^{m} \sum_{j=1}^{n} x_{i j}^{(1)} \geq \sum_{j=1}^{n} \sum_{k=1}^{p} x_{j k}^{(2)}, \\
& \sum_{i=1}^{m} \sum_{j=1}^{n} y_{i j}^{(1)} \geq \sum_{j=1}^{n} \sum_{k=1}^{p} y_{j k}^{(2)} .
\end{aligned}
$$

Prices are nonnegative variables as functions of the quantities.

Consumers buy the product through three different channels: material links from retailers, electronic links from retailers and electronic links from producers. Consumer's (market) $k(k=1,2$, $\ldots, p$ ) demands are decreasing functions of prices

$$
\begin{aligned}
& D_{k}^{(1)}=D_{k}^{(1)}\left(p^{(2)}\right), \\
& D_{k}^{(2)}=D_{k}^{(2)}\left(q^{(2)}\right), \\
& D_{k}^{(3)}=D_{k}^{(3)}\left(q^{(3)}\right) .
\end{aligned}
$$

Producer's i profit is expressed as follows:

$$
\begin{aligned}
z_{i}^{(1)} & =\sum_{j=1}^{n} p^{(1)} x_{i j}^{(1)}+\sum_{j=1}^{n} q^{(1)} y_{i j}^{(1)}+\sum_{k=1}^{p} q^{(3)} y_{i k}^{(3)}- \\
& -c_{i}^{(1)}\left(\sum_{j=1}^{n} x_{i j}^{(1)}+\sum_{j=1}^{n} y_{i j}^{(1)}+\sum_{k=1}^{p} y_{i k}^{(3)}\right)-\sum_{j=1}^{n} c_{i j}^{(1)} x_{i j}^{(1)}- \\
& -\sum_{j=1}^{n} d_{i j}^{(1)} y_{i j}^{(1)}-\sum_{k=1}^{p} d_{i k}^{(3)} y_{i k}^{(3)}
\end{aligned}
$$

Equilibrium conditions for producers $(i=1,2, \ldots, m)$ are given by the following equality system:

$$
\begin{gathered}
\frac{\partial z_{i}^{(1)}}{\partial x_{i j}^{(1)}}=\frac{\partial p^{(1)}}{\partial x_{i j}^{(1)}} x_{i j}^{(1)}+p^{(1)}-c_{i}^{(1)}-c_{i j}^{(1)}=0, j=1,2, \ldots, n, \\
\frac{\partial z_{i}^{(1)}}{\partial y_{i j}^{(1)}}=\frac{\partial q^{(1)}}{\partial y_{i j}^{(1)}} y_{i j}^{(1)}+q^{(1)}-c_{i}^{(1)}-d_{i j}^{(1)}=0, j=1,2, \ldots, n,
\end{gathered}
$$


$\frac{\partial z_{i}^{(1)}}{\partial y_{i k}^{(3)}}=\frac{\partial q^{(3)}}{\partial y_{i k}^{(3)}} y_{i k}^{(3)}+q^{(3)}-c_{i}^{(1)}-d_{i k}^{(3)}=0, k=1,2, \ldots, p$

Retailer's $j$ profit is expressed as follows:

$$
\begin{aligned}
z_{i}^{(2)} & =\sum_{k=1}^{p} p^{(2)} x_{j k}^{(2)}+\sum_{k=1}^{p} q^{(2)} y_{j k}^{(2)}-c_{j}^{(2)}\left(\sum_{k=1}^{p} x_{j k}^{(2)}+\right. \\
& \left.+\sum_{j=1}^{n} y_{j k}^{(2)}\right)-\sum_{k=1}^{p} c_{j k}^{(2)} x_{j k}^{(2)}-\sum_{j=1}^{n} d_{j k}^{(2)} y_{j k}^{(2)}
\end{aligned}
$$

Equilibrium conditions for producers $(j=1,2, \ldots, n)$ are given by the following equality system:

$$
\begin{gathered}
\frac{\partial z_{j}^{(2)}}{\partial x_{j k}^{(2)}}=\frac{\partial p^{(2)}}{\partial x_{j k}^{(2)}} x_{j k}^{(2)}+p^{(2)}-c_{j}^{(2)}-c_{j k}^{(2)}=0, k=1,2, \ldots, p, \\
\frac{\partial z_{j}^{(2)}}{\partial y_{j k}^{(2)}}=\frac{\partial q^{(2)}}{\partial y_{j k}^{(2)}} y_{j k}^{(2)}+q^{(2)}-c_{j}^{(2)}-d_{j k}^{(2)}=0, k=1,2, \ldots, p .
\end{gathered}
$$

Equilibrium conditions for customers $(k=1,2, \ldots, p)$ are given by the following equality system:

$$
\begin{aligned}
& D_{k}^{(1)}=\sum_{j=1}^{n} x_{j k}^{(2)}, \\
& D_{k}^{(2)}=\sum_{j=1}^{n} y_{j k}^{(2)}, \\
& D_{k}^{(3)}=\sum_{i=1}^{m} y_{i k}^{(3)} .
\end{aligned}
$$

The equilibrium state for the supply chain network is given by a set of equilibrium conditions (1), (2) and (3) for quantities of product shipment and prices.

\section{Modeling of cooperation in supply chains}

The layers of producers and retailers compete in a non-cooperative way but the partners in individual supply chains can profit from cooperative decision-making. The strategic partnership (see [8], [15]) means cooperation and coordination of actions through the supply chain. The strategic partnerships change material, financial and information flows among participants in the supply chain. Information centralizing using information technology changes the way of information sharing. The expected result is a mutually beneficial, win-win partnership that creates a synergistic supply chain in which the entire chain is more effective than the sum of its individual parts. Supply chain partnership leads to increased information flows, reduced uncertainty, and a more profitable supply chain.

The general supplier-customer relations in supply chain can be taken as centralized or decentralized (see [3]). The partnership relations are based on supply contracts. Contracts provide a means for bringing the decentralized solution to the centralized solution. Contracts also facilitate long-term partnership by delineating mutual concessions that favor the persistence of the relationship, as well a specifying penalty for non-cooperative behavior. The contracts are evaluated by multiple criteria as price, quantity, costs, time and quality and so on. There are different approaches to modeling multicriteria negotiation processes to reach a consensus among partners. A cooperative decision-making requires free communication among agents and gives synergical effects in a conflict resolution. The basic trend in the cooperative decision-making is to transform a possible conflict to a joint problem.

Some basic ideas of formal approaches to the problem solving can be introduced to cooperative decision-making. There are two aspects of the problem solving - representation and searching. The state space representation introduces the concepts of states and operators. An operator transforms one state into another state. A solution could be obtained by a search process, first applies operators to the initial state to produce new states and so on, until the goal state is produced. Communication between producers and retailers can be provided through information sharing (schematically see Fig. 5).

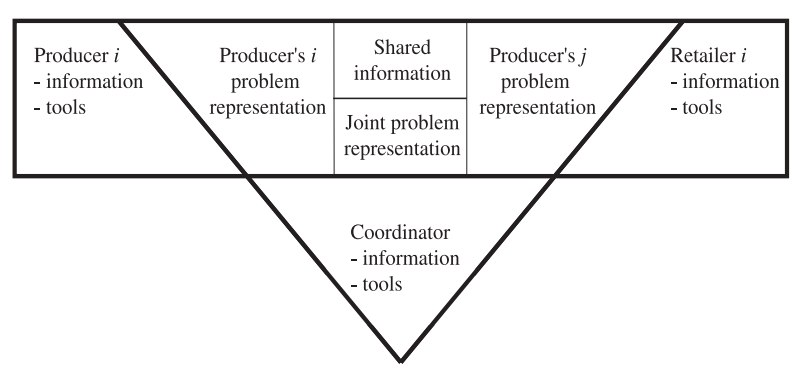

Fig. 5. Communication through information sharing

The proposed model is a discrete dynamic model and the cooperation of units is based on contracts and formal agreements achieved in negotiation process. We propose a two phases' interactive approach for solving cooperative decision making problems (see [2]):

1. Finding the ideal solution for individual agents.

2. Finding a consensus for all the agents.

In the first phase every decision maker search the ideal alternative by the assertivity principle. In the second phase the search process could obtain a consensus and the principle of cooperativeness is applied. The heuristic information for the decision-making unit is the distance between his proposal and the opponent's proposal.

The negotiation process modeling in general is a complex problem based on several kernel ideas. The framework (see [4]) of the proposed discrete dynamic model is separated to three parts:

- deterministic part,

- logical part,

- stochastic part. 
According to these three parts the modeling framework is composed from three inter-related network structures:

- flow network,

- Petri network,

- neural network.

The flow network represents the supply chain network with information, material and financial flows between partners. Petri network is used to coordinate asynchronous events of different units in the supply chain and to model negotiation process. The neural network serves as an instrument for inductive learning of negotiation strategies.

Producers and retailers in individual supply chains negotiate contracts about prices, quantities, costs, time etc. The double marginalization problem can be generalized and producers and retailers negotiate the profit sharing contracts.

\section{Conclusions}

Supply chain management has generated a substantial amount of interest both by managers and researchers. The interest has also been fueled by the growth in the development and application of e-business technologies. E-business is associated with business models and practices enabling continuous improvements in supply chains. Supply chain management is more and more affected by network business environment and by information and communication technologies. The network economy is characterized by massive global connectivity relationship among economic subjects.

The paper is devoted to the modeling of supply chains in network economy environment. In the model some important features of this environment are established. The presented model considers three-layer network structures of producers, retailers and customers. A possibility of e-commerce is also introduced. The layers of producers and retailers compete in a non-cooperative way but the partners in individual supply chains can profit from cooperative decision-making. The combination of non-cooperative and cooperative behavior of network users is more realistic.

The research project was supported by Grant No. 402/01/0771 from the Grant Agency of the Czech Republic "Modeling of Supply Chains" and CEZ: J 18/98: 311401001 from the University of Economics "Models and Methods for Economic Decisions".

\section{References}

[1] ECONOMIDES, N.: The Economics of Networks. International Journal of Industrial Organization 14, no. 2, 1996.

[2] FIALA, P.: Models of cooperative decision making. In: Multiple Criteria Decision Making (T. Gal and G. Fandel, eds.), pp. 128-136. Springer, Berlin 1997.

[3] FIALA, P.: Modeling of relations in supply chains. Vision: The Journal of Business Perspective. Special Issue on Supply Chain Management, Vol. 7, 2003,pp. 127-131.

[4] FIALA, P., KUKAL, J.: Modeling of cooperation in network production systems. APORS 2000, Singapore 2000.

[5] ISHIDA, T. (ed.): Community Computing - Collaboration over Global Information Networks. Wiley, New York 1998.

[6] KELLY, K.: New Rules for the New Economy: 10 Radical Strategies for a Connected World. Viking Press, New York 1998.

[7] KREPS, D.: Game Theory and Economic Modelling. Oxford University Press, Oxford 1991.

[8] MACBETH, D. K., FERGUSON, N.: Partnership Sourcing: An Integrated Supply Chain Management Approach. Pitman Publishing, London 1994.

[9] A. NAGURNEY, A.: Network Economics: A Variational Inequality Approach. Kluwer Academic Publishers, Dordrecht 1999.

[10] NAGURNEY, A., DONG, J.: Supernetworks: Decision-Making for the Information Age. Edward Elgar Publishers, Cheltenham 2002.

[11] SHAPIRO, C., VARIAN, H.: Information Rules: A Strategic Guide to the Network Economy. Harvard Business School Press, Boston 1999.

[12] SHY, O.: The Economics of Network Industries. Cambridge University Press, Cambridge 2001.

[13] SIMCHI-LEVI, D., KAMINSKY, P., SIMCHI-LEVI, E.: Designing and Managing the Supply Chain: Concepts, Strategies and Case studies. Irwin/ Mc Graw-Hill, 1999.

[14] TAYUR, S., GANESHAN, R., MAGAZINE, M.: Quantitative models for supply chain management, Kluwer, Boston 1999.

[15] THOMAS, D. J., GRIFFIN, P. M.: Coordinated Supply Chain Management. European Journal of Operational Research 94, 1996, 1-15.

[16] TIMMERS, P.: Electronic Commerce: Strategies and Models for Business-to-Business Trading. John Wiley, Chichester 1999.

[17] VIDAL, C. J., GOETSCHALCKX, M.: Strategic production-distribution models: A critical review with emphasis on global supply chain models. European Journal of Operational Research 98, 1997, 1-18. 